\title{
The Relationship between Mitochondrial Function and Walking Performance in Older Adults with a Wide Range of Physical Function
}

\author{
Adam J. Santanasto ${ }^{1}$, Paul M. Coen ${ }^{4,5}$, Nancy W. Glynn ${ }^{1}$, Kevin E. Conley ${ }^{3}$ Sharon A. Jubrias ${ }^{3}$, \\ Francesca Amati ${ }^{2,6}$, Elsa S. Strotmeyer ${ }^{1}$, Robert M. Boudreau ${ }^{1}$, Bret H. Goodpaster ${ }^{2,5}$ and Anne \\ B. Newman ${ }^{1}$
}

${ }^{1}$ Center for Aging and Population Health, Department of Epidemiology, Graduate School of Public Health, University of Pittsburgh, Pittsburgh, United States

${ }^{2}$ Division of Endocrinology and Metabolism, School of Medicine, University of Pittsburgh, Pittsburgh, United States

${ }^{3}$ Translational Center for Metabolic Imaging, University of Washington, Seattle, United States

${ }^{4}$ Department of Health and Physical Activity, School of Education, University of Pittsburgh, Pittsburgh, United States

Corresponding Author:

Anne B. Newman, PhD, MPH

130 DeSoto Street, A527 Crabtree Hall

Pittsburgh, PA 15261, United States

$+1-412.624 .3056$ (phone)

$+1-412.624 .3737$ (fax)

email:newmana@edc.pitt.edu; CC: kileym@edc.pitt.edu

${ }^{5}$ Current affiliation for Drs. Goodpaster and Coen: Translational Research Institute for Metabolism and Diabetes | Sanford Burnham, Orlando, USA

${ }^{6}$ Current affiliation for Dr. Amati: University of Lausanne, Switzerland

(C) 2016. This manuscript version is made available under the Elsevier user license http://www.elsevier.com/open-access/userlicense/1.0/ 


\section{ABSTRACT - 244 Words}

Background: Age related declines in walking performance may be partly attributable to skeletal muscle mitochondrial dysfunction as mitochondria produce over $90 \%$ of ATP needed for movement and the capacity for oxidative phosphorylation decreases with age.

Methods: Participants were from two studies: an ancillary to the Lifestyle Interventions and Independence for Elders (LIFE) Study $(n=33)$, which recruited lower functioning participants (Short Physical Performance Battery [SPPB], $7.8 \pm 1.2$ ), and the Study of Energy and AgingPilot (SEA, $n=29$ ), which enrolled higher functioning (SPPB, $10.8 \pm 1.4$ ). Physical activity was measured objectively using the Actigraph accelerometer (LIFE) and SenseWear Pro armband (SEA). Phosphocreatine recovery following muscle contraction of the quadriceps was measured using ${ }^{31} \mathrm{P}$ magnetic resonance spectroscopy and ATPmax (mM ATP/s) was calculated. Walking performance was defined as time (s) to walk $400 \mathrm{~m}$ at a usual-pace. The cross-sectional association between mitochondrial function and walking performance was assessed using multivariable linear regression.

Results: Participants were $77.6 \pm 5.3$ years, $64.2 \%$ female and $67.2 \%$ white. ATPmax was similar in LIFE vs. SEA $(0.52 \pm 0.14$ vs. $0.55 \pm 0.14, p=0.31)$, despite different function and activity levels $(1.6 \pm 2.2$ vs.77.4 \pm 73.3 min of moderate activity/day, $p<0.01)$. Higher ATPmax was related to faster walk-time in SEA $\left(\mathrm{r}^{2}=0.19, p=0.02,\right)$; but not the LIFE $\left(\mathrm{r}^{2}<0.01, p=\right.$ 0.74) cohort.

Conclusions: Mitochondrial function was associated with walking performance in higher functioning, active older adults, but not lower functioning, sedentary older adults.

Key Words: Mitochondrial Function, Mobility, Aging, Muscle, Physical Performance; Walking Performance 


\section{INTRODUCTION}

Walking performance decreases significantly with age, but with considerable individual variation (1). The underlying causes of age-related slowing are of great interest as slower gait is an independent risk factor for institutionalization (2) and mortality (3). The role of skeletal muscle in slowing walking performance is still unclear, as sarcopenia only modestly predicts mobility maintenance (or loss) in older adults (4). Further, maximum aerobic capacity $\left(\mathrm{VO}_{2}\right.$ peak) decreases with age independent of lean mass and physical activity levels (5). $\mathrm{VO}_{2}$ peak is partly dependent on the ability of skeletal muscle mitochondria to produce adenosine triphosphate (ATP) and mitochondria produce over $90 \%$ of ATP needed for movement (6). The capacity for mitochondrial oxidative phosphorylation is lower in aged compared to younger skeletal muscle, as both mitochondrial function and content are reduced (7-8). However, this age associated decrease in mitochondrial content and function may also be due in part to reduced physical activity and not completely attributable to aging per se (9). Thus, lower mitochondrial function may play a role in the age-related slowing of gait speed.

In fact, worse skeletal muscle mitochondrial function in older adults has been linked with higher fatigability (10), lower physical function (11) and slower gait speed (12). For example, Coen et al. showed that higher mitochondrial function was significantly associated with faster gait speed in higher functioning older adults (13). However, the relationship between mitochondrial function and walking performance has not been examined in older adults with both high and low levels of physical function. The purpose of this research was to examine the cross-sectional relationship between mitochondrial energetics, measured by ${ }^{31} \mathrm{P}$ magnetic 
resonance spectroscopy (MRS), and walking performance in older adults with a wide range of functional capacity.

\section{METHODS}

\section{Participants}

Participants were from two studies, employing identical measures of mobility and mitochondrial capacity for oxidative phosphorylation. The higher functioning cohort was from the Study of Energy in Aging-Pilot (SEA) $(10,13)$ and lower functioning participants were from an ancillary study to the Lifestyle Interventions and Independence for Elders (LIFE) Study (14).

SEA participants were community-dwelling $(n=37)$ men and women aged $70-89$ years from the Pittsburgh, PA area and inclusion and exclusion criteria have been described in detail elsewhere $(10,13)$. Briefly, inclusion criteria included body mass index $20-32 \mathrm{~kg} / \mathrm{m}^{2}$, ability to walk without an assistive device and free of basic activities of daily living disability. Exclusion criteria included history of hip fracture, heart attack, angioplasty, or heart surgery within the past 3 months, cerebral hemorrhage within the past 6 months, stroke within the past 12 months, or symptomatic cardiovascular or pulmonary disease. Participants were assessed at the magnetic resonance imaging (MRI) center for ${ }^{31} \mathrm{P}$ MRS scan eligibility for ability to lie in a supine position for 1-hour, no MR unsafe metal or other implants, bilateral joint replacements, and tattoos. The final analytical sample from SEA included 29 participants with complete MRS and 400m walk data. 
The LIFE Study was a multi-center randomized controlled trial designed to test the effectiveness of physical activity compared with health education on preventing mobility disability (14-15). Briefly, LIFE included sedentary adults aged 70-89, at high risk for mobility disability (Short Physical Performance Battery $[\mathrm{SPPB}, 0-12]$ score of $\leq 9)(16)$ but able to walk 400 meters in $<15$ minutes. LIFE study recruitment began in March of 2010 and ended in December of 2011 for the full study. In May 2011, LIFE participants from the Pittsburgh field center were screened, and if eligible, invited to take part in an ancillary study visit prior to starting their intervention program. The ancillary visit included a ${ }^{31} \mathrm{P}$ MRS scan, which had identical MR eligibility criteria to SEA. There were 91 LIFE participants randomized during this time and of these: $17(18.7 \%)$ refused, 35 (38.5\%) were ineligible (28 due to MR unsafe implants or bilateral knee/hip replacements) and 39 (42.9\%) were eligible to participate in the MR ancillary study. Of the 39 eligible participants, 33 had useable MRS data, yielding a final LIFE analytic sample of 33. Thus, the final analytic sample included 29 SEA and 33 LIFE participants (total $n=62$ ).

Both LIFE and SEA study protocols were approved by the University of Pittsburgh Institutional Review Board. All participants provided written informed consent.

\section{Clinic Examination and Measurements}

Participants completed clinic visits at the Health Studies Research Center at the University of Pittsburgh. Body height $(\mathrm{cm})$ was measured using a wall-mounted stadiometer and body weight $(\mathrm{kg})$ with a standard certified, calibrated scale, and used to calculate BMI $\left(\mathrm{kg} /\left(\mathrm{m}^{2}\right)\right.$. Participants completed demographic and self-reported health questionnaires. Questions were phrased in a similar manner between studies with one exception: history of arthritis. In SEA, the 
question asked about any history of arthritis, whereas LIFE asked about a doctor's visit in the past 6-months for arthritis or rheumatism. Diabetes was defined as either self-reported diagnosis, use of diabetic hypoglycemic medication or fasting blood glucose $\geq 126 \mathrm{mg} / \mathrm{dL}$.

Lower extremity function was assessed using the SPPB, a widely used performance measure scored on a 0-12 point scale. The test includes 3 parts: a $4 \mathrm{~m}$ walk; 5 timed, repeated chair stands; and a balance battery each worth 0-4 points (16). Seven-day free-living physical activity was measured in both studies; LIFE used the Actigraph ${ }^{\text {TM }}$ accelerometer (model GT3X, ActiGraph, LLC), while SEA employed the SenseWear ${ }^{\mathrm{TM}}$ Pro armband (BodyMedia, Pittsburgh, PA). NHANES cut-points (17) were used to categorize Actigraph counts, while the Sensewear's proprietary algorithm was used to calculate minutes per day spent in moderate and above ( $\geq 3$ METs) intensity activities.

\section{0-Meter Walk}

Walk protocols for both studies were nearly identical (13-14). The only difference was that LIFE permitted use of a single pronged cane. In both studies the test was conducted on a level ground 20-meter course. Participants were instructed to walk at their usual pace, without overexertion for 10 laps (20m up and back). Following the walk, participants from both studies were asked "Is anything bothering you?" and reported symptoms were recorded. Discomfort following the walk was defined as responding yes to this question. One SEA participant of the original 37 was excluded from analyses due to not completing the $400 \mathrm{~m}$ walk. 


\section{Determination of ATP ${ }_{\max }$ by ${ }^{31} \mathbf{P}$ MRS}

MRS protocols were identical and both studies utilized the same MR magnet, technician and MRS analyst. Phosphocreatine (PCr) recovery after exercise (ATPmax) was used to quantify mitochondrial capacity for oxidative phosphorylation. ${ }^{31} \mathrm{P}$ MRS has been validated by animal and human studies showing that ATPmax varies in direct proportion to oxidative enzyme activity of healthy muscle (18) and mitochondrial content in human muscle (7). ATPmax has good reproducibility illustrated by previously published Bland Altman analysis from SEA (19).

The exercise protocol was performed in an MRI magnet (3T TIM Trio, Siemens' Medical System) (10,13). Participants laid supine with the right knee (unless contraindicated) elevated at $\sim 30^{\circ}$. Straps were placed over the legs and a $2.5^{\prime \prime}$ surface RF coil tuned to ${ }^{31} \mathrm{P}$ was placed over the quadriceps. Participants performed repeated voluntary, rapid, maximal isometric contractions (kicking) for two bouts (30s and 36s) followed by a 6-minute rest. The protocol was designed to deplete $\mathrm{PCr}$ by $33-66 \%$ without inducing acidosis $(\mathrm{pH}<6.8)$. A monoexponential fit of $[\mathrm{PCr}]$ recovery yields the recovery constant $(\mathrm{k})$ for use in calculating $\mathrm{ATP}_{\max }$ :

$$
\mathrm{ATP}_{\max }=[\mathrm{PCr}]_{\mathrm{rest}} \bullet_{\mathrm{PCr}} \text {. }
$$

Previous analyses of human vastus lateralis muscle biopsies revealed that ATP content accounted for the range of PCr/ATP levels among participants aged 65-80 years (7). In contrast, PCr was stable (as was total creatine) and averaged $27 \mathrm{mM}$. Thus, we used $27 \mathrm{mM}$ for $[\mathrm{PCr}]_{\text {rest }}(10,13)$. Finally, we determined $\mathrm{pH}$ from the chemical shift of the Pi peak relative to the PCr peak (20). 


\section{Statistical Analyses}

The final analytic sample included 29 SEA and 33 LIFE participants with complete ATPmax and 400m data (total $n=62$ ). Baseline characteristics, means and standard deviations for continuous variables and frequencies and percents for categorical variables, were generated for each study. To test for between study differences, Wilcoxon rank-sum, chi-squared and Fischer's exact tests were used where appropriate.

To determine the relationship between ATPmax and 400m walk time (s) multivariable linear regression was used. We present results for each group separately. Bivariate and multivariable models adjusted for age, sex, race, study and BMI were generated. The beta coefficients represent the difference in 400m walk time (in seconds) per 1 SD higher ATPmax $(0.14 \mathrm{mM}$ atp/s). Since it is has been shown that those with type 2 diabetes have impaired mitochondrial function(21), we also examined the effect of diabetes on the relationship between ATPmax and 400m walk time. Physical activity was considered last because it is a known determinant of muitochondrial function, as we have previously shown(13,22). All analyses were performed with SAS version 9.3.

\section{RESULTS}

\section{Baseline Comparison of SEA and LIFE Study Participants}

LIFE compared with SEA participants were significantly more overweight, less active, had lower SPPB scores, and slower 400m walk times (Table 1). Of note, only one SEA participant had an SPPB score $<9$, an inclusion criteria for LIFE. LIFE also contained a 
significantly larger proportion of females and African Americans as well as a higher prevalence of diabetes and fewer reporting consuming 6 or more drinks per (Table 1). Despite significantly lower physical function and activity levels, LIFE had similar ATPmax compared with SEA (0.55 \pm 0.14 vs. $0.52 \pm 0.14 \mathrm{mM} \mathrm{ATP} / \mathrm{s}, p=0.31)$.

Table 1. Characteristics by Study and in Combination

\begin{tabular}{|c|c|c|c|}
\hline & $\begin{array}{c}\text { SEA }(n=29) \\
\text { Mean }(\mathrm{SD}) \text { or } N(\%)\end{array}$ & $\begin{array}{c}\text { LIFE }(n=33) \\
\text { Mean (SD) or } N(\%)\end{array}$ & $\begin{array}{c}\text { P-value for } \\
\text { between study } \\
\text { difference }\end{array}$ \\
\hline Age, yrs & $78.6(5.0)$ & $76.6(5.5)$ & 0.14 \\
\hline Sex , female & $13(44.8)$ & $25(75.8)$ & 0.01 \\
\hline Race, white & $27(93.1)$ & $16(48.5)$ & $<0.01$ \\
\hline BMI, $\mathrm{kg} / \mathrm{m}^{2}$ & $26.0(2.7)$ & $30.8(5.4)$ & $<0.01$ \\
\hline Smoker, current or former & $10(34.5)$ & $9(27.3)$ & 0.54 \\
\hline Alcohol, 6+ drinks/week & $8(27.6)$ & $2(6.1)$ & 0.04 \\
\hline Diabetes & $1(3.5)$ & $9(27.3)$ & 0.01 \\
\hline Myocardial infarction & $3(10.3)$ & $1(3.0)$ & 0.33 \\
\hline $\begin{array}{l}\text { Chronic obstructive pulmonary } \\
\text { disease }\end{array}$ & $1(3.5)$ & $3(9.1)$ & 0.62 \\
\hline
\end{tabular}




\begin{tabular}{|l|cc|c|} 
Arthritis & $9(31.0)$ & $6(18.2)$ & 0.24 \\
Moderate and above activity, & $77.4(73.3)$ & $1.6(2.2)$ & $<0.01$ \\
min/day & $10.8(1.4)$ & $7.8(1.2)$ & $<0.01$ \\
SPPB, 0-12 & $343.8(65.5)$ & $466.9(110.1)$ & $<0.01$ \\
D00m walk time, s & $5(17.2)$ & $12(36.4)$ & 0.09 \\
ATPcomfort at end of 400m walk, yes & $0.52(0.14)$ & $0.55(0.14)$ & 0.31 \\
\hline
\end{tabular}

In LIFE, 12 (36.4\%) participants reported discomfort at the end of the walk compared with 5 (17.2\%) from SEA (Table 1). More specifically, in LIFE, 3 participants reported back pain, 3 reported hip pain, 2 reported knee pain, 2 reported light headedness, 1 reported tiredness and foot pain, while 1 requested their straight cane due to general discomfort. In SEA, the 5 participants who reported discomfort reported the following symptoms: shortness of breath and back pain, knee and calf pain, back pain, hip and calf pain, and foot pain.

\section{Relationship between ATPmax and 400m Walk Time}

Higher levels of ATPmax were significantly related to faster $400 \mathrm{~m}$ walk time in SEA ( $B$ $=-29.3, p=0.02$ ), with ATPmax explaining $19 \%$ of the variance in walk time (Table 2, Figure 1). However, no association was observed in LIFE ( $(\beta=6.2, p=0.74$, Table 2, Figure 1). After adjustment for age, sex, race and BMI, the relationship between ATPmax and 400m walk time in the SEA was attenuated slightly $(\beta=-24.8, p=0.08)$. Adding diabetes to the fully adjusted 
models had no effect on the relationship between ATPmax and walk time (SEA: $p=0.95$; LIFE: $p=0.52$ for diabetes parameter) and there was no interaction between ATPmax and diabetes on walking time in either cohort (SEA: $p>0.99$; LIFE: $p=0.15$ ). Physical activity was uniformly low in LIFE and not associated with ATPmax $(r=-0.06, p=0.75)$, while it was in SEA $(r=$ $0.48, \mathrm{p}<0.01)$, as we have previously shown $(13,22)$.

Table 2. Association between ATPmax and Time to Walk 400 meters by Study and in Combination

\begin{tabular}{|c|c|c|c|}
\hline Model & $\begin{array}{c}\text { Beta, } \mathrm{s}^{\S} \\
(\text { per } 0.14 \mathrm{mM} / \mathrm{ATP} / \mathrm{s})\end{array}$ & SE & $\begin{array}{c}p \text { - } \\
\text { value }\end{array}$ \\
\hline SEA $(n=29)$ - Unadjusted & -29.3 & 11.6 & 0.02 \\
\hline SEA - Adjusted* & -24.8 & 13.3 & 0.08 \\
\hline LIFE $(n=33)$ - Unadjusted & 6.2 & 19.5 & 0.75 \\
\hline LIFE - Adjusted* & 26.0 & 16.0 & 0.11 \\
\hline
\end{tabular}

SE: standard error

*adjusted for age, race, sex and BMI

${ }^{\S}$ beta coefficients represent the difference in $400 \mathrm{~m}$ walk time (in seconds) per $1 \mathrm{SD}$ higher ATPmax (0.14 $\mathrm{mM}$ atp/s). 


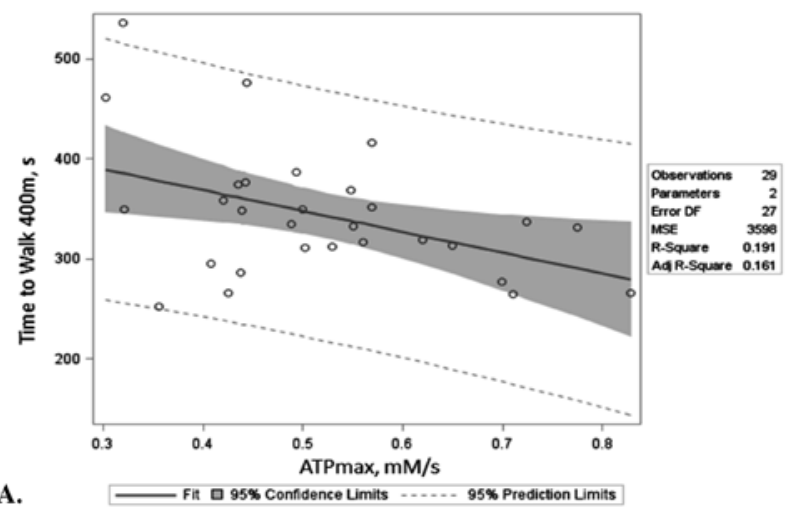

A.

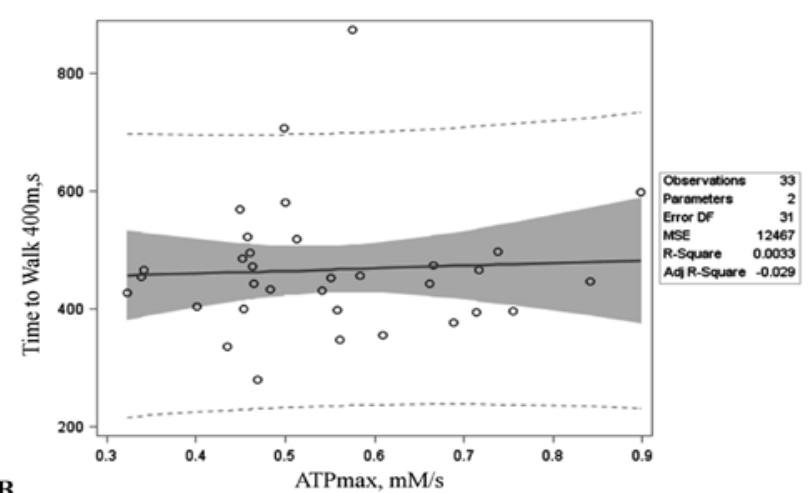

Figure 1. Relationship between ATPmax and 400m Walk in SEA (A) and LIFE (B)

\section{Caption for Figure 1.}

ATPmax is defined as phosphocreatine recovery in the quadriceps following an acute bout of exercise measured by ${ }^{31} \mathrm{P}$ magnetic resonance spectroscopy. Unadjusted $p$-values and bivariate $\mathrm{r}^{2}$ values for the relationship between ATPmax and $400 \mathrm{~m}$ walk time were as follows: A.) $\mathrm{r}^{2}=0.19$, $p=0.02$ for SEA and B.) $\mathrm{r}^{2}<0.01, p=0.75$ for LIFE. 


\section{DISCUSSION}

High ATPmax was associated with faster time to walk $400 \mathrm{~m}$ in higher functioning, active SEA participants, but not lower functioning, sedentary LIFE participants. This lack of an association is contrary to hypotheses generated from our previous work (13) as well as several other studies of older adults (11-12,23). Namely, higher mitochondrial function measured by ${ }^{31} \mathrm{P}$ MRS was related to faster time to complete a get-up-and-go-test in French, lower functioning hospitalized $(n=49$, aged $86.1 \pm 5.3$ years) and higher functioning community-dwelling older adults ( $\mathrm{n}=28$, aged $74.5 \pm 6.2$ years) (12). Similarly, a muscle biopsy study in relatively younger (aged $62.0 \pm 11.8$ ) peripheral artery disease patients showed that higher mitochondrial function was related to longer walking time during a $\mathrm{VO}_{2}$ max test (23). Importantly, both of the previously mentioned studies measured mitochondrial function in the gastrocnemius muscle $(12,23)$, whereas the current study used the quadriceps. The conflicting results could be attributable to studying different muscle groups, as previous cross-sectional work suggests aging may affect locomotory muscles differently (24). However, the vastus lateralis (VL) muscle, the muscle of interest in the current study, may be more susceptible to age and physical activity related changes compared to the tibialis anterior muscle (24). Therefore, in theory the VL muscle would have been more closely associated with age related decreases in walking performance. Further, a study from Joseph et al. showed that participants with lower mitochondrial respiration rates and markers of biogenesis in permeabilized muscle fibers from the VL are also significantly more likely to have lower SPPB scores (11). Although both are locomotory muscles of the lower leg, perhaps mitochondrial function in the gastrocnemius and tibialis anterior muscles undergo 
heterogeneous age-related changes possibly due to gait biomechanics. This issue requires further investigation in studies examining the relationship between walking performance and mitochondrial function in different muscle groups from the same individual. Further, longitudinal studies of different muscle groups are needed to truly understand the effects of age and physical activity on mitochondrial function.

Another key finding was that ATPmax levels were nearly identical between SEA and LIFE even though the LIFE participants were much less physically active and lower functioning. This conflicts with two studies showing that sedentary older adults have impaired mitochondrial function compared with active (25) and a second finding that lower functioning older adults possess worse mitochondrial bioenergetics compared with higher functioning as measured by the SPPB (11). These conflicting results may in part be explained by the different measures of mitochondrial function, as the two abovementioned studies used biopsy measures. However, ATPmax reflects in-vitro measures of mitochondrial function(13); perhaps ATPmax does not correlate as well with biopsy measures in lower function individuals. Future methodological work should investigate these associations in low functioning participants.

The inconsistencies concerning the relationship between ATPmax and walking performance could be attributable to our walking performance measure (400m walk); however, lower functioning individuals walk closer to their maximal performance during a usual paced $400 \mathrm{~m}$ walk compared with higher functioning (26). Therefore, since ATPmax is highly related to $\mathrm{VO}_{2}$ peak (13), a stronger relationship would have been expected in the lower functioning LIFE participants. Unless the LIFE participants had other impairments limiting walking performance, unrelated to oxidative capacity of the quadriceps, such as pain or joint stiffness. Indeed, although 
the difference did not reach statistical significant, over twice the proportion of LIFE participants reported discomfort, mainly due to pain, during the walk compared with SEA ( $36 \%$ vs. $17 \%$ ).

There are several possible explanations for why ATPmax was unrelated to $400 \mathrm{~m}$ walk time in lower functioning participants. First, there may be differences in muscle mass that could affect walking time independent of ATPmax; however LIFE was lacking a measure of muscle mass. The, the higher prevalence of discomfort and pain experience by LIFE participants during the walk may have caused them to slow down for reasons unrelated to mitochondrial function. Joint impairments (27), arthritis (28), knee (29) and back pain (30) are associated with slower walking speed or physical disability in older adults. Secondly, the LIFE Study was lacking a measure of mitochondrial efficiency $(\mathrm{P} / \mathrm{O})$, which is related to exercise efficiency in older adults (31). Finally, since discomfort and pain may evoke alterations to normal gait (32), it is plausible that those with both higher levels of ATPmax and slower walk times were biomechanically inefficient. Thus, these participants may be producing more energy (ATP) to walk at the same speed (or more slowly) than a biomechanically efficient individual. Indeed, higher energy cost of walking $\left(\mathrm{VO}_{2}\right.$ normalized to gait speed) is related to worse biomechanical gait parameters (3334) and impaired mobility (34-36). This may cause a less biomechanically efficient individual to have a higher ATPmax than their activity level or walking speed would suggest, which may also partially explain the phenomenon of similar ATPmax levels observed in SEA compared with LIFE. However, we cannot rule out the mediating role of other factors related to $\mathrm{VO}_{2}$ peak such as cardiopulmonary function. Further investigations are needed, particularly in lower functioning older adults, to further understand the interrelationships between ATPmax, gait biomechanics, energy cost of walking and walking performance. 
Strengths of this study include a larger sample size compared with previous work examining the relationship between skeletal muscle mitochondrial energetics and walking performance in older adults and including a diverse population in terms of sex, race, function and physical activity levels. Mitochondrial function was measured directly and in vivo using ${ }^{31} \mathrm{P}$ MRS. Performance measures, as opposed to self-report, were used to quantify physical function and walking speed. Limitations include participants being from two separate studies; however, the study sites, primary outcome and predictor were identical. Muscle biopsies were not obtained in the LIFE cohort, so mitochondrial efficiency and other parameters could not be determined. The study was cross-sectional, thus no causal inferences can be made. Despite being the largest study to have examined these relationships to date, the sample size was still relatively small, which limited our ability to stratify by possible mediating/confounding factors, particularly those that differed across the study populations, or test for interactions.

In conclusion, our study provides important and novel insights into the role of skeletal muscle mitochondrial capacity for oxidative phosphorylation in walking performance in older adults. Specifically, ATPmax (functional oxidative capacity of the quadriceps) was unrelated to walking times in lower functioning, sedentary participants and those with a wide range of function. However, higher mitochondrial function was related to faster walking times in higher functioning, active participants. This suggests that lower mitochondrial function may be a marker of early functional decline in higher functioning older adults. Further, mitochondrial function does not appear to be a limiting factor in lower functioning participants, who may slow for other reasons such as pain while ambulating. Larger studies examining other aspects mitochondrial 
energetics, energy cost and physical performance in older adults with wide age (e.g. aged 50-85) and physical function ranges are needed to further investigate these relationships.

\section{FUNDING:}

This work was supported by the National Institute on Aging/National Institutes of Health (grant number 1RC2AG036594-01 - SEA-P) as well The University of Pittsburgh, Center for Aging and Population Health: Pilot Grant Program and the Department of Epidemiology: Student Small Grant Program (LIFE-MITO). Adam Santanasto was supported by a Ruth L. Kirschstein National Research Service Award from the NIA (T32-AG-000181). Paul Coen is supported by a career development award from the National Institute on Aging (AG044437).

\section{ACKNOWLEDGMENTS:}

SEA participants were recruited using the Pittsburgh Claude D. Pepper Older Americans Independence Center Research Registry (P30 AG024827).

\section{Research Investigators and Funding for the LIFE Main Study}

The Lifestyle Interventions and Independence for Elders Study is funded by a National Institutes of Health/National Institute on Aging Cooperative Agreement \#UO1 AG22376 and a supplement from the National Heart, Lung and Blood Institute 3U01AG022376-05A2S, and sponsored in part by the Intramural Research Program, National Institute on Aging, NIH. 
The research is partially supported by the Claude D. Pepper Older Americans Independence Centers at the University of Florida (1 P30 AG028740), Wake Forest University (1 P30 AG21332), Tufts University (1P30AG031679), University of Pittsburgh (P30 AG024827), and Yale University (P30AG021342) and the NIH/NCRR CTSA at Stanford University (UL1 RR025744), Tufts University is also supported by the Boston Rehabilitation Outcomes Center (1R24HD065688-01A1).

LIFE investigators are also partially supported by the following:

Dr. Thomas Gill (Yale University) is the recipient of an Academic Leadership Award (K07AG3587) from the National Institute on Aging.

Dr. Carlos Fragoso (Spirometry Reading Center, Yale University) is the recipient of a Career Development Award from the Department of Veterans Affairs.

Dr. Roger Fielding (Tufts University) is partially supported by the U.S. Department of Agriculture, under agreement No. 58-1950-0-014. Any opinions, findings, conclusion, or recommendations expressed in this publication are those of the author(s) and do not necessarily reflect the view of the U.S. Dept of Agriculture.

\section{Administrative Coordinating Center, University of Florida, Gainesville, FL}

Marco Pahor, MD - Principal Investigator of the LIFE Study

Jack M. Guralnik, MD, PhD - Co-Investigator of the LIFE Study (University of Maryland School of Medicine, Baltimore, MD)

Christiaan Leeuwenburgh, $\mathrm{PhD}$

Connie Caudle

Lauren Crump, MPH

Latonia Holmes 
Jocelyn Lee, PhD

Ching-ju Lu, MPH

Data Management, Analysis and Quality Control Center, Wake Forest University, Winston

Salem, NC

Michael E. Miller, PhD - DMAQC Principal Investigator

Mark A. Espeland, PhD - DMAQC Co-Investigator

Walter T. Ambrosius, $\mathrm{PhD}$

William Applegate, MD

Daniel P. Beavers, PhD, MS

Robert P. Byington, PhD, MPH, FAHA

Delilah Cook, CCRP

Curt D. Furberg, MD, PhD

Lea N. Harvin, BS

Leora Henkin, MPH, Med

John Hepler, MA

Fang-Chi Hsu, PhD

Laura Lovato, MS

Wesley Roberson, BSBA

Julia Rushing, BSPH, MStat

Scott Rushing, BS

Cynthia L. Stowe, MPM

Michael P. Walkup, MS

Don Hire, BS 
W. Jack Rejeski, PhD

Jeffrey A. Katula, PhD, MA

Peter H. Brubaker, $\mathrm{PhD}$

Shannon L. Mihalko, PhD

Janine M. Jennings, PhD

National Institutes of Health, Bethesda, MD

Evan C. Hadley, MD (National Institute on Aging)

Sergei Romashkan, MD, PhD (National Institute on Aging)

Kushang V. Patel, PhD (National Institute on Aging)

National Heart, Lung and Blood Institute, Bethesda, MD

Denise Bonds, MD, MPH

\section{Field Centers}

Northwestern University, Chicago, IL

Mary M. McDermott, MD - Field Center Principal Investigator

Bonnie Spring, PhD - Field Center Co-Investigator

Joshua Hauser, MD - Field Center Co-Investigator

Diana Kerwin, MD - Field Center Co-Investigator

Kathryn Domanchuk, BS

Rex Graff, MS

Alvito Rego, MA

Pennington Biomedical Research Center, Baton Rouge, LA

Timothy S. Church, MD, PhD, MPH - Field Center Principal Investigator

Steven N. Blair, PED (University of South Carolina) 
Valerie H. Myers, PhD

Ron Monce, PA-C

Nathan E. Britt, NP

Melissa Nauta Harris, BS

Ami Parks McGucken, MPA, BS

Ruben Rodarte, MBA, MS, BS

Heidi K. Millet, MPA, BS

Catrine Tudor-Locke, PhD, FACSM

Ben P. Butitta, BS

Sheletta G. Donatto, MS, RD, LDN, CDE

Shannon H. Cocreham, BS

Stanford University, Palo Alto, CA

Abby C. King, PhD - Field Center Principal Investigator

Cynthia M. Castro, PhD William L. Haskell, PhD

Randall S. Stafford, MD, PhD Leslie A. Pruitt, PhD

Kathy Berra, MSN, NP-C, FAAN

Veronica Yank, MD

Tufts University, Boston, MA

Roger A. Fielding, PhD - Field Center Principal Investigator

Miriam E. Nelson, PhD - Field Center Co-Investigator

Sara C. Folta, PhD - Field Center Co-Investigator

Edward M. Phillips, MD

Christine K. Liu, MD 
Erica C. McDavitt, MS

Kieran F. Reid, PhD, MPH

Dylan R. Kirn, BS

Evan P. Pasha, BS

Won S. Kim, BS

Vince E. Beard, BS

Eleni X. Tsiroyannis, BS

Cynthia Hau, BS, MPH

University of Florida, Gainesville, FL

Todd M. Manini, PhD - Field Center Principal Investigator

Marco Pahor, MD - Field Center Co-Investigator

Stephen D. Anton, PhD

Susan Nayfield, MD

Thomas W. Buford, PhD

Michael Marsiske, $\mathrm{PhD}$

Bhanuprasad D. Sandesara, MD

Jeffrey D. Knaggs, BS

Megan S. Lorow, BS

William C. Marena, MT, CCRC

Irina Korytov, MD

Holly L. Morris, MSN, RN, CCRC (Brooks Rehabilitation Clinical Research Center, Jacksonville, FL)

Margo Fitch, PT (Brooks Rehabilitation Clinical Research Center, Jacksonville, FL) 
Floris F. Singletary, MS, CCC-SLP (Brooks Rehabilitation Clinical Research Center, Jacksonville, FL)

Jackie Causer, BSH, RN (Brooks Rehabilitation Clinical Research Center, Jacksonville, FL)

Katie A. Radcliff, MA (Brooks Rehabilitation Clinical Research Center, Jacksonville, FL)

University of Pittsburgh, Pittsburgh, PA

Stephanie A. Studenski, MD, MPH - Field Center Co-Investigator

Oscar Lopez, MD

Neelesh K. Nadkarni, MD, PhD

Kathy Williams, RN, BSEd, MHSA

Mark A. Newman, PhD

George Grove, MS

Janet T. Bonk, MPH, RN

Jennifer Rush, MPH

Piera Kost, BA (deceased)

Diane G. Ives, MPH

Wake Forest University, Winston Salem, NC

Stephen B. Kritchevsky, Ph.D. - Field Center Principal Investigator

Anthony P. Marsh, PhD - Field Center Co-Investigator

Tina E. Brinkley, PhD

Jamehl S. Demons, MD

Kaycee M. Sink, MD, MAS

Kimberly Kennedy, BA, CCRC

Rachel Shertzer-Skinner, MA, CCRC 
Abbie Wrights, MS

Rose Fries, RN, CCRC

Deborah Barr, MA, RHEd, CHES

Yale University, New Haven, CT

Thomas M. Gill, MD - Field Center Principal Investigator

Robert S. Axtell, PhD, FACSM - Field Center Co-Investigator (Southern Connecticut State

University, Exercise Science Department)

Susan S. Kashaf, MD, MPH (VA Connecticut Healthcare System)

Nathalie de Rekeneire, MD, MS

Joanne M. McGloin, MDiv, MS, MBA

Karen C. Wu, RN

Denise M. Shepard, RN, MBA

Barbara Fennelly, MA, RN

Lynne P. Iannone, MS, CCRP

Raeleen Mautner, $\mathrm{PhD}$

Theresa Sweeney Barnett, MS, APRN

Sean N. Halpin, MA

Matthew J. Brennan, MA

Julie A. Bugaj, MS

Maria A. Zenoni, MS

Bridget M. Mignosa, AS LIFE

Cognition Coordinating Center, Wake Forest University, Winston Salem, NC

Jeff Williamson, MD, MHS - Center Principal Investigator 
Kaycee M Sink, MD, MAS - Center Co-Investigator

Hugh C. Hendrie, MB, ChB, DSc (Indiana University)

Stephen R. Rapp, PhD

Joe Verghese, MB, BS (Albert Einstein College of Medicine of Yeshiva University)

Nancy Woolard

Mark Espeland, $\mathrm{PhD}$

Janine Jennings, PhD

Valerie K. Wilson, MD

Electrocardiogram Reading Center, University of Florida, Gainesville, FL

Carl J. Pepine MD, MACC

Mario Ariet, $\mathrm{PhD}$

Eileen Handberg, PhD, ARNP

Daniel Deluca, BS

James Hill, MD, MS, FACC

Anita Szady, MD

Spirometry Reading Center, Yale University, New Haven, CT

Geoffrey L. Chupp, MD

Gail M. Flynn, RCP, CRFT

Thomas M. Gill, MD

John L. Hankinson, PhD (Hankinson Consulting, Inc.)

Carlos A. Vaz Fragoso, MD

Cost Effectiveness Analysis Center 
Erik J. Groessl, PhD (University of California, San Diego and VA San Diego Healthcare System)

Robert M. Kaplan, PhD (Office of Behavioral and Social Sciences Research, National Institutes of Health)

A preliminary version of this work was presented at the 2013 Annual Meeting of the Gerontological Society of America in New Orleans, Louisiana (Poster Session 510). 


\section{References}

1. Newman AB, Arnold AM, Sachs MC, et al. Long-term function in an older cohort--the cardiovascular health study all stars study. J Am Geriatr Soc. 2009;57:432-440. 10.1111/j.15325415.2008.02152.x

2. Hornyak V, VanSwearingen JM, Brach JS. Measurement of gait speed. Topics in Geriatric Rehabilitation. 2012;28:27-32.

3. Studenski S, Perera S, Patel K, et al. Gait Speed and Survival in Older Adults. JAMA: The Journal of the American Medical Association. 2011;305:50-58. 10.1001/jama.2010.1923

4. Janssen I. Influence of Sarcopenia on the Development of Physical Disability: The Cardiovascular Health Study. Journal of the American Geriatrics Society. 2006;54:56-62. $10.1111 / \mathrm{j} .1532-5415.2005 .00540 . \mathrm{x}$

5. Fleg JL, Morrell CH, Bos AG, et al. Accelerated Longitudinal Decline of Aerobic Capacity in Healthy Older Adults. Circulation. 2005;112:674-682.

10.1161/circulationaha.105.545459

6. Rolfe DF, Brown GC. Cellular energy utilization and molecular origin of standard metabolic rate in mammals. Physiological Reviews. 1997;77:731-758.

7. Conley KE, Jubrias SA, Esselman PC. Oxidative capacity and ageing in human muscle. The Journal of Physiology. 2000;526:203-210. 10.1111/j.1469-7793.2000.t01-1-00203.x 
8. Short KR, Bigelow ML, Kahl J, et al. Decline in skeletal muscle mitochondrial function with aging in humans. Proceedings of the National Academy of Sciences of the United States of America. 2005;102:5618-5623. 10.1073/pnas.0501559102

9. Russ DW, Kent-Braun JA. Is Skeletal Muscle Oxidative Capacity Decreased in Old Age? Sports Med. 2004;34:221-229. 10.2165/00007256-200434040-00002

10. Santanasto AJ, Glynn NW, Jubrias SA, et al. Skeletal Muscle Mitochondrial Function and Fatigability in Older Adults. The Journals of Gerontology Series A: Biological Sciences and Medical Sciences. 2014. 10.1093/gerona/glu134

11. Joseph AM, Adhihetty PJ, Buford TW, et al. The impact of aging on mitochondrial function and biogenesis pathways in skeletal muscle of sedentary high- and low-functioning elderly individuals. Aging Cell. 2012;11:801-809. 10.1111/j.1474-9726.2012.00844.x

12. Bourdel-Marchasson I, Biran M, Dehail P, et al. Muscle phosphocreatine post-exercise recovery rate is related to functional evaluation in hospitalized and community-living older people. J Nutr Health Aging. 2007;11:7.

13. Coen PM, Jubrias SA, Distefano G, et al. Skeletal Muscle Mitochondrial Energetics Are Associated With Maximal Aerobic Capacity and Walking Speed in Older Adults. The Journals of Gerontology Series A: Biological Sciences and Medical Sciences. 2013;68:447-455. 10.1093/gerona/gls196 
14. Fielding RA, Rejeski WJ, Blair S, et al. The Lifestyle Interventions and Independence for Elders Study: Design and Methods. The Journals of Gerontology Series A: Biological Sciences and Medical Sciences. 2011;66A:1226-1237. 10.1093/gerona/glr123

15. Pahor M, Guralnik JM, Ambrosius WT, et al. Effect of structured physical activity on prevention of major mobility disability in older adults: the LIFE study randomized clinical trial. JAMA. 2014;311:2387-2396. 10.1001/jama.2014.5616

16. Guralnik JM, Ferrucci L, Pieper CF, et al. Lower Extremity Function and Subsequent Disability. The Journals of Gerontology Series A: Biological Sciences and Medical Sciences. 2000;55:M221-M231. 10.1093/gerona/55.4.M221

17. Matthews CE, Chen KY, Freedson PS, et al. Amount of time spent in sedentary behaviors in the United States, 2003-2004. American journal of epidemiology. 2008;167:875881. 10.1093/aje/kwm390

18. Paganini AT, Foley JM, Meyer RA. Linear dependence of muscle phosphocreatine kinetics on oxidative capacity. American Journal of Physiology - Cell Physiology. 1997;272:C501-C510.

19. Santanasto AJ, Simonsick EM, Ferrucci LM, et al. Perceived Fatigability is Associated with Mobility and Performance in Older Adults. Gerontological Society of America, National Meeting. San Diego, CA; 2012.

20. Heineman F, Eng J, Berkowitz B, Balaban R. NMR spectral analysis of kinetic data using natural lineshapes. Magnetic resonance in medicine. 1990;13:490-497. 
21. Kelley DE, He J, Menshikova EV, Ritov VB. Dysfunction of Mitochondria in Human Skeletal Muscle in Type 2 Diabetes. Diabetes. 2002;51:2944-2950. 10.2337/diabetes.51.10.2944

22. Santanasto AJ, Glynn NW, Jubrias SA, et al. Skeletal Muscle Mitochondrial Function and Fatigability in Older Adults. The Journals of Gerontology Series A: Biological Sciences and Medical Sciences. 2015;70:1379-1385. 10.1093/gerona/glu134

23. Hou XY, Green S, Askew CD, Barker G, Green A, Walker PJ. Skeletal muscle mitochondrial ATP production rate and walking performance in peripheral arterial disease. Clinical Physiology and Functional Imaging. 2002;22:226-232. 10.1046/j.1475097X.2002.00423.X

24. Larsen RG, Callahan DM, Foulis SA, Kent-Braun JA. Age-related changes in oxidative capacity differ between locomotory muscles and are associated with physical activity behavior. Applied Physiology, Nutrition, and Metabolism. 2012;37:88-99. 10.1139/h11-135

25. Safdar A, Hamadeh MJ, Kaczor JJ, Raha S, deBeer J, Tarnopolsky MA. Aberrant Mitochondrial Homeostasis in the Skeletal Muscle of Sedentary Older Adults. PLoS ONE. 2010;5:e10778. 10.1371/journal.pone.0010778

26. Lange-Maia B, Newman A, Strotmeyer E, Harris T, Caserotti P, Glynn N. Performance on fast- and usual-paced 400-m walk tests in older adults: are they comparable? Aging Clin Exp Res. 2015;27:309-314. 10.1007/s40520-014-0287-y

27. Gibbs J, Hughes S, Dunlop D, Singer R, Chang RW. Predictors of change in walking velocity in older adults. J Am Geriatr Soc. 1996;44:126-132. 
28. Al-Zahrani KS, Bakheit AMO. A study of the gait characteristics of patients with chronic osteoarthritis of the knee. Disability and Rehabilitation. 2002;24:275-280. doi:10.1080/09638280110087098

29. Powers CM, Perry J, Hsu A, Hislop HJ. Are Patellofemoral Pain and Quadriceps Femoris Muscle Torque Associated With Locomotor Function? Physical Therapy. 1997;77:1063-1075.

30. Rudy TE, Weiner DK, Lieber SJ, Slaboda J, Boston JR. The impact of chronic low back pain on older adults: A comparative study of patients and controls. PAIN. 2007;131:293301. http://dx.doi.org/10.1016/j.pain.2007.01.012

31. Conley KE, Jubrias SA, Cress ME, Esselman P. Exercise efficiency is reduced by mitochondrial uncoupling in the elderly. Experimental Physiology. 2013;98:768-777. 10.1113/expphysiol.2012.067314

32. Kuo AD, Donelan JM. Dynamic principles of gait and their clinical implications. Phys Ther. 2010;90:157-174. 10.2522/ptj.20090125

33. Wert DM, Brach J, Perera S, VanSwearingen JM. Gait Biomechanics, Spatial and Temporal Characteristics, and the Energy Cost of Walking in Older Adults with Impaired Mobility. Physical Therapy. 2010;90:977-985. 10.2522/ptj.20090316

34. Malatesta D, Simar D, Dauvilliers Y, et al. Energy cost of walking and gait instability in healthy 65- and 80-yr-olds. J Appl Physiol (1985). 2003;95:2248-2256.

10.1152/japplphysiol.01106.2002 
35. Richardson CA, Glynn NW, Ferrucci LG, Mackey DC. Walking Energetics, Fatigability, and Fatigue in Older Adults: The Study of Energy and Aging Pilot. The Journals of Gerontology Series A: Biological Sciences and Medical Sciences. 2014. 10.1093/gerona/glu146

36. Schrack JA, Simonsick EM, Ferrucci L. The Energetic Pathway to Mobility Loss: An Emerging New Framework for Longitudinal Studies on Aging. Journal of the American Geriatrics Society. 2010;58:S329-S336. 10.1111/j.1532-5415.2010.02913.x 